\title{
Use of Spirulina platensis in place of vitamin mineral premix on the performance of broiler
}

\author{
KMS Islam* , P Roy, MR Debi and M Kamruzzaman
}

Department of Animal Nutrition, Bangladesh Agricultural University, Mymensingh

\begin{abstract}
The experiment was conducted to compare the effects of different sources of Spirulina and vitamin mineral premix as feed additive on the growth performance of broiler. Two hundred day old broiler chicks (COBB-500) were divided into five groups such as $\mathrm{T}_{1}$-(Feed containing $0.30 \%$ Vitamin mineral premix $+0.0 \%$ Spirulina), $\mathrm{T}_{2}$-(Feed containing $0.15 \%$ Vitamin mineral premix $+0.15 \%$ Spirulina from China), $\mathrm{T}_{3}$-(Feed containing $0.0 \%$ Vitamin mineral premix $+0.30 \%$ Spirulina from China), $\mathrm{T}_{4}$-(Feed containing $0.15 \%$ Vitamin mineral premix $+0.15 \%$ Spirulina from Myanmar) and $\mathrm{T}_{5}$-(Feed containing $0.0 \%$ Vitamin mineral premix $+0.30 \%$ Spirulina from Myanmar) having four replication in each group containing 10 birds/replication. The experiment was conducted for 28 days (Completely Randomized Design) with ad libitum feed and water. Live weight was numerically higher $(P>0.05)$ in $T_{4}$ in $4^{\text {th }}$ weeks of age. Lower feed intake observed in $\mathrm{T}_{3}$ and $\mathrm{T}_{5}$ which was mainly $50 \%$ replacement of vitamin mineral premix by Spirulina. After end of the feeding trial feed conversion ratio (1.66) in control group was higher $(P<0.05)$ than other groups $\left(1.63,1.64,1.59\right.$ and 1.61 respectively in $T_{2}, T_{3}, T_{4}$ and $\left.T_{5}\right)$. Dressing percentage $(63.12 \%)$, breast weight $(21.22 \%)$ and thigh weight $(8.54 \%)$ were higher $(\mathrm{P}<0.05)$ in $\mathrm{T}_{4}$ than all other groups. Concentration of total cholesterol in blood plasma $(64.42 \mathrm{mg} / \mathrm{dl})$ and serum albumin $(1.75 \mathrm{~g} / \mathrm{dl})$ was lower $(P<0.05)$ in $\mathrm{T}_{4}$. It could be concluded that Spirulina from Myanmar is better than China and $50 \%$ synthetic vitamin mineral premix could be replaced by using Spirulina from Myanmar for better growth of broiler.
\end{abstract}

Keywords: broiler performance, vitamin-mineral premix, blood profile, feed conversion ratio, spirulina

Bangladesh Animal Husbandry Association. All rights reserved.

Bang. J. Anim. Sci. 2020. 49 (2):151-158

\section{Introduction}

Poultry industry is growing very fast during last three decades and expanding rapidly than other food producing animal industries. The net trade volume of poultry products has also increased parallel to the rapid growth of global poultry meat and egg production (Windhorst, 2006). At present the ultimate aim of poultry industry is the attainment of sustainable broiler production in the shortest possible time in order to give access of people to animal protein source with minimum cost. However, the major constraints of livestock production in developing countries are the scarcity and fluctuating quantity and quality of the year-round feed supply. Providing an adequate good-quality feed to broiler to raise and maintain their productivity in proper way will be a major challenge to agricultural scientists and policy makers all over the world. For this large number of poultry production, the feed production will have to be increased. Among the feed ingredients the vitamin-mineral premix is one of the most costly items. As a less costly substitute of vitamin-mineral premix algae can be an option. Algae production could be a promising alternative as a source of feed nutrient. The most commonly used algae species is Spirulina (Spirulina platensis). Spirulina is multicellular, blue-green algae. They are very small and microscopic and 300 to $500 \mu \mathrm{m}$ in length. These blue-green algae contain $50-70 \%$ protein, 10 $12 \%$ carbohydrate (in dry condition), $6 \%$ fat, $7 \%$ minerals and a lot of vitamins (Shuvo, 2001). It is rich in B vitamins, minerals, trace elements, chlorophylls and enzymes (Kelly et al., 1995). Considerable amounts of phosphorous, magnesium zinc and pepsin found in Spirulina platensis. It also consist $6-11 \%$ polysaccharide; the predominant are palmitic $(16: 0,44.6-54.1 \%)$ gama-linolenic acid or GLA (18:3, 8.0-31.7\%), linoleic (18:2, 10.8-30.7\%) and oleic acids (18:1, $1.0-15.5 \%)$. It has been used for last ten years as a model organism in many studies on outdoor cultivation of algal biomass as a source of proteins (Richmond, 1987). Spirulina species not only contribute in human health but also plays considerable role as animal feed. It increases the yellowness and redness in broiler flesh when 
Spirulina fed with diet (Habib et al., 2008). Feeding on Spirulina helped to improve disease resistance of some high valued fish which resulting in increase in their survival rate from $85.0 \%$. When Spirulina was added to forage for poultry and livestock, their growth rate was improved (Toyomizu et al., 2001). It is generally accepted to be a good source of protein (60$70 \%)$, essential amino acids (1.30-2.75\% on DM basis), vitamins, minerals, essential fatty acids and antioxidant pigments (Holman and MalauAduli, 2012). Chickens receiving diets supplemented with Spirulina had better health might be due to an enhancement of the immune function (Belay et al., 1996). Inclusion of Spirulina in layer diets has also been shown to reduce total cholesterol content of eggs while increasing omega-3 fatty acid levels (Sujatha and Narahari, 2011).

Therefore, the present work was undertaken to study the replacement of Vitamin mineral premix by Spirulina (Spirulina platensis) in broiler diet from different sources for the growth performance, carcass characteristics and blood profiles of broiler.

\section{Materials and Methods}

The experiment was conducted in the poultry rearing unit of Shahjalal Animal Nutrition Field
Laboratory, Bangladesh Agricultural University, Mymensingh for a period of 28 days.

\section{Chicks, ingredients and Spirulina}

Day old broiler chicks (COBB-500) were purchased from CP Bangladesh Ltd. All the feed ingredients were collected from local market in Mymensingh town and Spirulina were collected from Myanmar (JUNE Pharmaceuticals Limited) and China (Jiangxi Yuchang Industry Co., Ltd). Vitamin mineral premix was collected from Renata Limited. The ingredients and nutritional composition of different dietary treatments are presented in Table 1 and 2, respectively.

\section{Experimental design and ration formulation}

Total number of 200 chicks was distributed into 5 groups having 4 replication floor cages containing 10 birds in each cage as mentioned below.

$\mathrm{T}_{1}$ - (Feed containing $0.30 \%$ Vitamin mineral premix $+0.0 \%$ Spirulina)

$\mathrm{T}_{2^{-}}$(Feed containing $0.15 \%$ Vitamin mineral premix $+0.15 \%$ Spirulina from China)

$\mathrm{T}_{3^{-}}$(Feed containing $0.0 \%$ Vitamin mineral premix $+0.30 \%$ Spirulina from China)

$\mathrm{T}_{4^{-}}$(Feed containing $0.15 \%$ Vitamin mineral premix $+0.15 \%$ Spirulina from Myanmar)

$\mathrm{T}_{5^{-}}$(Feed containing $0.0 \%$ Vitamin mineral premix $+0.30 \%$ Spirulina from Myanmar)

Table 1: Formulation of diet (\%) in different experimental groups

\begin{tabular}{lccccc}
\hline \multirow{2}{*}{\multicolumn{1}{c}{ Ingredients }} & \multicolumn{5}{c}{ Treatment groups } \\
\cline { 2 - 6 } & $\mathbf{T}_{\mathbf{1}}$ & $\mathbf{T}_{\mathbf{2}}$ & $\mathbf{T}_{\mathbf{3}}$ & $\mathbf{T}_{\mathbf{4}}$ & $\mathbf{T}_{\mathbf{5}}$ \\
\hline Maize & 53.0 & 53.0 & 53.0 & 53.0 & 53.0 \\
Protein Concentrate & 12.0 & 12.0 & 12.0 & 12.0 & 12.0 \\
Rice polish & 3.00 & 3.00 & 3.00 & 3.00 & 3.00 \\
Soybean meal & 23.0 & 23.0 & 23.0 & 23.0 & 23.0 \\
DCP & 1.50 & 1.50 & 1.50 & 1.50 & 1.50 \\
Vitamin mineral premix & 0.30 & 0.15 & 0.00 & 0.15 & 0.00 \\
Spirulina from China & 0.00 & 0.15 & 0.30 & 0.00 & 0.00 \\
Spirulina from Myanmer & 0.00 & 0.00 & 0.00 & 0.15 & 0.30 \\
Salt & 0.50 & 0.50 & 0.50 & 0.50 & 0.50 \\
DL-Methionine & 0.15 & 0.15 & 0.15 & 0.15 & 0.15 \\
Choline Chloride & 0.05 & 0.05 & 0.05 & 0.05 & 0.05 \\
Soybean oil & 2.75 & 2.75 & 2.75 & 2.75 & 2.75 \\
Starch & 3.75 & 3.75 & 3.75 & 3.75 & 3.75 \\
Total & 100 & 100 & 100 & 100 & 100 \\
\hline
\end{tabular}

$T_{1}$-(Feed containing $0.30 \%$ Vitamin mineral premix $+0.0 \%$ Spirulina) $; T_{2}$-(Feed containing $0.15 \%$ Vitamin mineral premix $+0.15 \%$ Spirulina from China); $T_{3}$-(Feed containing $0.0 \%$ Vitamin mineral premix $+0.30 \%$ Spirulina from China) $; T_{4}$ (Feed containing $0.15 \%$ Vitamin mineral premix $+0.15 \%$ Spirulina from Myanmar); $T_{5}{ }^{-}$ (Feed containing $0.0 \%$ Vitamin mineral premix $+0.30 \%$ Spirulina from Myanmar). 
Islam et al. (2020) Bang. J. Anim. Sci. 49 (2):151-158

Table 2: Nutritional composition ( $\mathrm{g} / 100 \mathrm{~g}$ fresh) of different treatment groups

\begin{tabular}{lccccc}
\hline Parameter & $\mathbf{T}_{\mathbf{1}}$ & $\mathbf{T}_{\mathbf{2}}$ & $\mathbf{T}_{\mathbf{3}}$ & $\mathbf{T}_{\mathbf{4}}$ & $\mathbf{T}_{\mathbf{5}}$ \\
\hline Dry Matter & 88.41 & 88.20 & 89.33 & 88.72 & 89.37 \\
Crude Protein & 22.84 & 22.79 & 22.20 & 22.66 & 22.60 \\
Crude Fibre & 3.65 & 3.41 & 3.59 & 3.73 & 3.29 \\
Ether Extract & 5.33 & 5.69 & 5.95 & 6.22 & 6.48 \\
Ash & 5.93 & 5.81 & 5.41 & 5.99 & 5.77 \\
\hline
\end{tabular}

$T_{1}$-(Feed containing $0.30 \%$ Vitamin mineral premix $+0.0 \%$ Spirulina) $; T_{2}$-(Feed containing $0.15 \%$ Vitamin mineral premix $+0.15 \%$ Spirulina from China); $T_{3}$ (Feed containing $0.0 \%$ Vitamin mineral premix $+0.30 \%$ Spirulina from China) $; T_{4}$-(Feed containing $0.15 \%$ Vitamin mineral premix $+0.15 \%$ Spirulina from Myanmar) $; T_{5^{-}}$ (Feed containing $0.0 \%$ Vitamin mineral premix $+0.30 \%$ Spirulina from Myanmar).

\section{General management}

Two hundred COBB-500 commercial day old broiler chicks were reared in this experiment having average weight of $45.33 \mathrm{~g} /$ bird. 20 cages required for this trial each having floor space of $0.91 \mathrm{~m}^{2}(120 \mathrm{~cm} \times 76 \mathrm{~cm})$. Fresh dried saw dust was used as litter material and maintained properly throughout the experiment. Every week litter was stirred to prevent accumulation of ammonia gas and maggot formation. A 100-watt electric bulb was used for each cage to maintain proper lighting and brooding. The chicks were distributed 10 birds per cages where feeders and waterers were placed previously. Feeds were supplied as ad libitum basis. Proper bio-security measures were also taken during the whole experimental period.

The birds were vaccinated against Newcastle Disease $\left(4^{\text {th }}\right.$ and $20^{\text {th }}$ day) and Infectious Bursal Disease $\left(11^{\text {th }}\right.$ day) intraocular. The broilers were examined twice a day for clinical sign (slow movement, infrequent sitting, lack of appetite, significant changes of feathering, paralysis etc.) recorded as per symptoms.

\section{Record keeping and collection of data}

Broilers were weighted in a group at the beginning of the trial and then every week at the age of day $0,7,14,21$ and 28 . Feed offered were recorded when supplied in cages and refusal at the end of each week also recorded. Feed intake, feed conversion ratio and feed conversion efficiency were calculated. Numbers of dead birds were counted during the whole experimental period.

Blood from healthy chicken was collected using 10 $\mathrm{ml}$ falcon tube directly from the heart after slaughtering at day 28 of age from randomly selected birds of each replication. After collection of blood samples, each tube was placed in a rack at room temperature. To avoid blood clot, EDTA was used and tubes were put in the centrifuge machine. The collected blood was centrifuged at
$1500 \mathrm{rpm}$ for 20 minutes to obtain plasma and transferred into sterile $1.5 \mathrm{ml}$ eppendorf tube. The plasma was preserved in deep freezer and the tubes were marked properly with permanent marker for easy identification during blood analysis.

Samples of feed ingredients (in duplicate) were analyzed to determine dry matter (DM), crude protein $(C P)$, ether extract (EE), crude fibre (CF), and total ash (Ash) following the method described by AOAC (1990).

\section{Statistical analysis}

All recorded and calculated variables were subjected to analysis of variance (ANOVA) in a Completely Randomized Design (CRD) by following a statistical package using SPSS statistical computer package program. Tukey Pairwise Comparisons was used to compare treatment means.

\section{Results}

\section{Live weight, feed intake and feed conversion ratio}

Live weight of broiler was different $(P<0.05)$ in last two weeks, $3^{\text {rd }}$ and $4^{\text {th }}$ weeks of age (Table 3 ). In $1^{\text {st }}$ weeks of age, live weight was higher in $\mathrm{T}_{3}$ and $\mathrm{T}_{4}$ (groups than other groups of birds. In $2^{\text {nd }}$ week, live weight was numerically higher inT $_{4}$ group. At $3^{\text {rd }}$ week, live weight was lower $(P<0.05)$ in $T_{5}$ group and higher in $T_{4}$ group. Finally higher live weight $(P<0.05)$ was obtained at $T_{4}$ and $T_{2}$ groups. In the present experiment replacement of $50.0 \%$ vitamin-mineral premix by adding $50.0 \%$ Spirulina of Myanmar had difference $(P<0.05)$ in live weight at different weeks of age of broiler. Finally $50.0 \%$ replacement of vitamin mineral premix by Spirulina from Maynmer would be suitable for better performance $(P<0.05)$ shown in group $\mathrm{T}_{4}$.Initial 2 weeks there was no difference among the groups for feed intake (Table 4). In $3^{\text {rd }}$ week feed intake $(P<0.05)$ was higher in $T_{4}$ and $T_{1}$ 
groups compared to other groups but no statistical variation was observed between two groups. In the $4^{\text {th }}$ weeks of age, highest feed intake $(P<0.05)$ was observed in the $T_{4}$ and $T_{2}$ and $\mathrm{T}_{1}$ groups, respectively. Feed conversion ratio at different weeks is presented in Table 5 .
Initially it was lower $(\mathrm{P}<0.05)$ in $\mathrm{T}_{4}$ group. But second week it was numerically lower at $T_{4}$ and $\mathrm{T}_{3}$ groups, respectively. But at $3^{\text {rd }}$ week all the treatment groups except $T_{5}$ showed better FCR than control $\quad\left(T_{1}\right) \quad(P<0.05)$. Finally $T_{4}$ group showed better FCR than control $(P<0.05)$.

Table 3: Live weight of birds $(\mathrm{g})$ in different age supplemented with or without vitamin mineral premix or spirulina (Spirulinaplatensis)

\begin{tabular}{lccccc}
\hline \multirow{2}{*}{ Days } & \multicolumn{5}{c}{ Treatment groups } \\
\cline { 2 - 6 } & $\mathbf{T}_{\mathbf{1}}$ & $\mathbf{T}_{\mathbf{2}}$ & $\mathbf{T}_{\mathbf{3}}$ & $\mathbf{T}_{\mathbf{4}}$ & $\mathbf{T}_{\mathbf{5}}$ \\
\hline Day 0 & $45.0 \pm 1.0$ & $46.6 \pm 2.0$ & $45.7 \pm 2.0$ & $44.4 \pm 1.0$ & $45.0 \pm 2.0$ \\
Day 7 & $147.01 \pm 20.0$ & $158.0 \pm 19.1$ & $165.0 \pm 18.3$ & $179.0 \pm 3.1$ & $147.0 \pm 9.5$ \\
Day 14 & $344.2 \pm 33.4$ & $372.1 \pm 44.6$ & $375.0 \pm 56.1$ & $372.0 \pm 29.7$ & $346.0 \pm 13.1$ \\
Day 21 & $753.0^{\mathrm{a}} \pm 39.1$ & $695.0^{\mathrm{ab}} \pm 15.7$ & $698.1^{\mathrm{a}} \pm 41.3$ & $797.0^{\mathrm{a}} \pm 30.5$ & $611.0^{\mathrm{c}} \pm 31.0$ \\
Day 28 & $1117.0^{\mathrm{b}} \pm 35.7$ & $1159.0^{\mathrm{b}} \pm 17.2$ & $1068.2^{\mathrm{bc}} \pm 20.0$ & $1220.0^{\mathrm{a}} \pm 24.1$ & $1100.2^{\mathrm{bc}} \pm 30.0$ \\
Day(0-28) & $1072.0^{\mathrm{bc}} \pm 35.4$ & $1112.3^{\mathrm{b}} \pm 15.1$ & $1022.3^{\mathrm{c}} \pm 57.7$ & $1175.0^{\mathrm{a}} \pm 40.1$ & $1055.0^{\mathrm{c}} \pm 30.8$ \\
\hline
\end{tabular}

Mean $\pm S D ;{ }^{a b c}$ Means with dissimilar superscripts are significantly different $(P<0.05) ; T_{1}$-(Feed containing 0.30 $\%$ Vitamin mineral premix $+0.0 \%$ Spirulina) $; T_{2}$ - (Feed containing $0.15 \%$ Vitamin mineral premix $+0.15 \%$ Spirulina from China); $T_{3}$-(Feed containing $0.0 \%$ Vitamin mineral premix $+0.30 \%$ Spirulina from China); $T_{4^{-}}$ (Feed containing $0.15 \%$ Vitamin mineral premix $+0.15 \%$ Spirulina from Myanmar); $T_{5}$-(Feed containing $0.0 \%$ Vitamin mineral premix $+0.30 \%$ Spirulina from Myanmar).

Table 4: Cumulative feed intake $(\mathrm{g})$ in different age of birds supplemented with or without vitamin mineral premix or spirulina (Spirulina platensis)

\begin{tabular}{lccccc}
\hline \multirow{2}{*}{ Days } & \multicolumn{5}{c}{ Treatment groups } \\
\cline { 2 - 6 } & $\mathbf{T}_{\mathbf{1}}$ & $\mathbf{T}_{\mathbf{2}}$ & $\mathbf{T}_{\mathbf{3}}$ & $\mathbf{T}_{\mathbf{4}}$ & $\mathbf{T}_{\mathbf{5}}$ \\
\hline Day (0-7) & $151.0 \pm 3.1$ & $164.1 \pm 13.0$ & $155.3 \pm 5.3$ & $164.2 \pm 6.1$ & $148.3 \pm 4.6$ \\
Day (0-14) & $452.0 \pm 31.0$ & $486.0 \pm 30.0$ & $460.0 \pm 10.4$ & $472.1 \pm 36.1$ & $464.0 \pm 15.7$ \\
Day(0-21) & $1109.1^{\mathrm{a}} \pm 35.0$ & $1012.0^{\mathrm{b}} \pm 46.7$ & $982.2^{\mathrm{b}} \pm 58.3$ & $1108.9^{\mathrm{a}} \pm 66.8$ & $897.0^{\mathrm{c}} \pm 47.0$ \\
Day(0-28) & $1787.3^{\mathrm{a}} \pm 67.8$ & $1806.5^{\mathrm{a}} \pm 74.2$ & $1676.7^{\mathrm{b}} \pm 50.9$ & $1869.2^{\mathrm{a}} \pm 70.0$ & $1698.7^{\mathrm{b}} \pm 94.4$ \\
\hline
\end{tabular}

Mean $\pm S D ;{ }^{a b c}$ Means with dissimilar superscripts are significantly different $(P<0.05) ; T_{1}$-(Feed containing 0.30 $\%$ Vitamin mineral premix $+0.0 \%$ Spirulina) $; T_{2}$ - (Feed containing $0.15 \%$ Vitamin mineral premix $+0.15 \%$ Spirulina from China) $; T_{3}$-(Feed containing $0.0 \%$ Vitamin mineral premix $+0.30 \%$ Spirulina from China) $; T_{4}$ (Feed containing $0.15 \%$ Vitamin mineral premix $+0.15 \%$ Spirulina from Myanmar); $T_{5}$-(Feed containing $0.0 \%$ Vitamin mineral premix $+0.30 \%$ Spirulina from Myanmar).

Table 5: Cumulative FCR (Kg FI/Kg LWG) in different age of birds supplemented with or without vitamin mineral premix or spirulina (Spirulina platensis)

\begin{tabular}{lccccc}
\hline \multirow{2}{*}{ Days } & \multicolumn{5}{c}{ Treatment groups } \\
\cline { 2 - 6 } & $\mathbf{T}_{\mathbf{1}}$ & \multicolumn{1}{c}{$\mathbf{T}_{\mathbf{2}}$} & \multicolumn{1}{c}{$\mathbf{T}_{\mathbf{3}}$} & $\mathbf{T}_{\mathbf{4}}$ & $\mathbf{T}_{\mathbf{5}}$ \\
\hline Day (0-7) & $1.48^{\mathrm{a}} \pm 0.13$ & $1.47^{\mathrm{a}} \pm 0.11$ & $1.30^{\mathrm{ab}} \pm 0.14$ & $1.22^{\mathrm{b}} \pm 0.03$ & $1.45^{\mathrm{a}} \pm 0.15$ \\
Day (0-14) & $1.52 \pm 0.17$ & $1.49 \pm 0.19$ & $1.40 \pm 0.09$ & $1.39 \pm 0.03$ & $1.54 \pm 0.13$ \\
Day (0-21) & $1.57^{\mathrm{a}} \pm 0.05$ & $1.56^{\mathrm{a}} \pm 0.04$ & $1.51^{\mathrm{ab}} \pm 0.04$ & $1.47^{\mathrm{b}} \pm 0.01$ & $1.57^{\mathrm{a}} \pm 0.05$ \\
Day (0-28) & $1.66^{\mathrm{a}} \pm 0.02$ & $1.63^{\mathrm{a}} \pm 0.06$ & $1.64^{\mathrm{ab}} \pm 0.16$ & $1.59^{\mathrm{b}} \pm 0.03$ & $1.61^{\mathrm{a}} \pm 0.14$ \\
\hline
\end{tabular}

Mean士 SD; ${ }^{a b c}$ Means with dissimilar superscripts are significantly different $(P<0.05) ; T_{1}$ - $($ Feed containing 0.30 $\%$ Vitamin mineral premix $+0.0 \%$ Spirulina); $T_{2}$ - (Feed containing $0.15 \%$ Vitamin mineral premix $+0.15 \%$ Spirulina from China) $; T_{3}$ (Feed containing $0.0 \%$ Vitamin mineral premix $+0.30 \%$ Spirulina from China) $; T_{4^{-}}$ (Feed containing $0.15 \%$ Vitamin mineral premix $+0.15 \%$ Spirulina from Myanmar); $T_{5}$-(Feed containing $0.0 \%$ Vitamin mineral premix $+0.30 \%$ Spirulina from Myanmar). 
Islam et al. (2020) Bang. J. Anim. Sci. 49 (2):151-158

Table 6: Carcass characteristics (\%) in different age of birds supplemented with or without vitamin mineral premix or spirulina (Spirulina platensis)

\begin{tabular}{lccccc}
\hline & \multicolumn{5}{c}{ Treatments } \\
\cline { 2 - 5 } & $\mathbf{T}_{\mathbf{1}}$ & $\mathbf{T}_{\mathbf{2}}$ & $\mathbf{T}_{\mathbf{3}}$ & $\mathbf{T}_{\mathbf{4}}$ & $\mathbf{T}_{\mathbf{5}}$ \\
\hline Breast & $21.66^{\mathrm{a}}$ & $20.49^{\mathrm{b}}$ & $19.63^{\mathrm{c}}$ & $21.22^{\mathrm{a}}$ & $19.38^{\mathrm{c}}$ \\
Thigh & $7.99^{\mathrm{c}}$ & $7.57^{\mathrm{c}}$ & $7.77^{\mathrm{b}}$ & $8.54^{\mathrm{a}}$ & $7.82^{\mathrm{b}}$ \\
Drumstick & $3.98^{\mathrm{d}}$ & $4.62^{\mathrm{a}}$ & $4.25^{\mathrm{c}}$ & $4.26^{\mathrm{b}}$ & $4.42^{\mathrm{b}}$ \\
Shank & 3.51 & 4.48 & 4.53 & 4.17 & 5.01 \\
Liver & $2.82^{\mathrm{c}}$ & $3.45^{\mathrm{a}}$ & $3.01^{\mathrm{b}}$ & $2.55^{\mathrm{d}}$ & $3.35^{\mathrm{a}}$ \\
Gizzard & $3.28^{\mathrm{c}}$ & $3.72^{\mathrm{a}}$ & $3.55^{\mathrm{b}}$ & $3.02^{\mathrm{d}}$ & $3.71^{\mathrm{a}}$ \\
Skin & 6.41 & 6.37 & 6.06 & 6.27 & 6.82 \\
Dressing & $62.05^{\mathrm{a}}$ & $61.08^{\mathrm{b}}$ & $60.27^{\mathrm{b}}$ & $63.12^{\mathrm{a}}$ & $57.42^{\mathrm{c}}$ \\
\hline percentage & & &
\end{tabular}

Mean; abcMeans with dissimilar superscripts are significantly different $(P<0.05) ; T_{1}$-(Feed containing $0.30 \%$ Vitamin mineral premix $+0.0 \%$ Spirulina) $; T_{2}$-(Feed containing $0.15 \%$ Vitamin mineral premix $+0.15 \%$ Spirulina from China); $T_{3}$-(Feed containing $0.0 \%$ Vitamin mineral premix $+0.30 \%$ Spirulina from China); $T_{4^{-}}$ (Feed containing $0.15 \%$ Vitamin mineral premix $+0.15 \%$ Spirulina from Myanmar); $T_{5}$-(Feed containing $0.0 \%$ Vitamin mineral premix $+0.30 \%$ Spirulina from Myanmar).

Table 7: Blood parameters in different age of birds supplemented with or without vitamin mineral premix or spirulina (Spirulina platensis)

\begin{tabular}{lccccc}
\hline \multirow{2}{*}{ Days } & \multicolumn{5}{c}{ Treatments } \\
\cline { 2 - 6 } & $\mathbf{T}_{\mathbf{1}}$ & $\mathbf{T}_{\mathbf{2}}$ & $\mathbf{T}_{\mathbf{3}}$ & $\mathbf{T}_{\mathbf{4}}$ & $\mathbf{T}_{\mathbf{5}}$ \\
\hline $\begin{array}{l}\text { Glucose } \\
(\mathrm{mmol} / \mathrm{L})\end{array}$ & $4.99 \pm 0.23^{\mathrm{b}}$ & $6.10 \pm 0.38^{\mathrm{b}}$ & $12.51 \pm 0.269^{\mathrm{a}}$ & $5.76 \pm 0.29^{\mathrm{b}}$ & $11.52 \pm 0.25^{\mathrm{a}}$ \\
$\begin{array}{l}\text { Creatinine } \\
(\mathrm{mg} / \mathrm{dL})\end{array}$ & $0.056 \pm 0.008^{\mathrm{c}}$ & $0.64 \pm 0.056^{\mathrm{a}}$ & $0.163 \pm 0.004^{\mathrm{bc}}$ & $0.114 \pm 0.003^{\mathrm{bc}}$ & $0.24 \pm 0.056^{\mathrm{b}}$ \\
$\begin{array}{l}\text { Urea }(\mathrm{mg} / \mathrm{dL}) \\
\text { Albumin }(\mathrm{g} / \mathrm{dL})\end{array}$ & $16.65 \pm 0.28$ & $16.53 \pm 0.032$ & $16.19 \pm 0.084$ & $16.65 \pm 0.21$ & $16.14 \pm 0.35$ \\
$\begin{array}{l}\text { Cholesterol } \\
(\mathrm{mg} / \mathrm{dL})\end{array}$ & $111.13 \pm 8.03^{\mathrm{a}}$ & $84.14 \pm 5.75^{\mathrm{bc}}$ & $86.25 \pm 6.63^{\mathrm{bc}}$ & $64.42 \pm 4.32^{\mathrm{c}}$ & $96.47 \pm 3.95^{\mathrm{ab}}$ \\
\hline
\end{tabular}

Mean $\pm S D ;{ }^{a b c}$ Means with dissimilar superscripts are significantly different $(P<0.05) ; T_{1}$ - $($ Feed containing 0.30 $\%$ Vitamin mineral premix $+0.0 \%$ Spirulina) $; T_{2}-$ (Feed containing $0.15 \%$ Vitamin mineral premix $+0.15 \%$ Spirulina from China); $T_{3}$-(Feed containing $0.0 \%$ Vitamin mineral premix $+0.30 \%$ Spirulina from China); $T_{4}{ }^{-}$ (Feed containing $0.15 \%$ Vitamin mineral premix $+0.15 \%$ Spirulina from Myanmar); $T_{5}$-(Feed containing $0.0 \%$ Vitamin mineral premix $+0.30 \%$ Spirulina from Myanmar).

\section{Carcass characteristics}

Dressing percentage was higher $(P<0.05)$ in $T_{4}$ where $50 \%$ synthetic vitamin mineral premix were replaced by $50 \%$ Spirulina from Myanmar than other groups of birds (Table 6). Breast weight was higher $(P<0.05)$ in $T_{4}$ and $T_{1}$. Drumstick was highest in $T_{2}$ and weight of thigh was also higher in $\mathrm{T}_{4}$.

\section{Blood profile}

Concentration of albumin (1.75) and cholesterol (64.42) in blood plasma were lower $(P<0.05)$ in $\mathrm{T}_{4}$ and higher $(P<0.05)$ in $T_{5}$ and $T_{1}$ (Table 7$)$. Glucose concentration was higher $(P<0.05)$ in $T_{3}$. Creatinine concentration (0.056) was lower $(P<0.05)$ in $T_{1}$ groups. 


\section{Discussion}

\section{Live weight, feed intake and feed conversion ratio}

Copper present in Spirulina helps in growth, improving feed efficiency and egg production (Pesti and Bakalli, 1998) and Spirulina rich in copper and phosphorus which helps in growth efficiency and protein synthesis in the body which supports the results of our experiment because the best live weight was found when $50 \%$ Spirulina was used in feed as a replacement of $50 \%$ synthetic vitamin-mineral premix. This is because all the minerals that are present in synthetic vitamin-mineral premix are not fully available in utilizable form for birds but phosphorus availability from Spirulinais $41.0 \%$ (Yoshida and Hoshii, 1980; Blum et al., 1976). Kharde et al. (2012) also agrees with the result of the present experiment as he gets the best growth rate when Spirulina were used at a rate of $0.30 \%$ with feed.Inclusion level of Spirulina affect the weight gain of broiler and in the present experiment live weight gain was highest in the control group where full synthetic vitamin-mineral premix is used and the closest result was found when $50 \%$ synthetic vitamin-mineral premix are replaced by Spirulina from Myanmar. Shanmugapriya et al. (2015) reported that dietary inclusion of $1.0 \%$ of Spirulina as compared to the control feed, body weight gain was significantly increased in broilers.

Devi et al. (1981) noted that Spirulina is approximately 65.0to 71.0 percent protein, depending on growing conditions and these proteins are biologically complete, which means they provide all eight essential amino acids in the proper ratios. Spirulina provides all the required amino acids in a form that is easier to digest than meat or soy protein (Devi et al., 1981). Amino acid in proper ratio are essential in different digestive enzyme synthesis, which enhance feed utilization and rate of passage through the digestive tract and for these reasons maximum feed intake was observed in those treatment where Spirulina were used as replacement of synthetic vitamin-mineral premix. Shanmugapriya et al. (2015) reported that dietary inclusion of $1.0 \%$ of Spirulina in broilers increased Villi length that indicates better feed utilization and feed intake. From morphological point of view, longer villi increased surface area that allowed greater absorption of available nutrients and enhance feed intake especially in the distal intestinal segment (Caspary, 1992). It was found that body weight, average daily weight gain, carcass yield percentage and feed conversion ratio improved by the dietary inclusion of the Spirulina as compared to the control (Khardeet al., 2012; Shanmugapriyaet al., 2015). Under oxidative stress conditions, there is an increased demand for antioxidants to reduce the deleterious effects of free radicals on the immune system (Carroll and Forsberg, 2007). Spirulinaplatensis, have been considered as a suitable natural antioxidant and immunestimulant to humans and animals with fewer side effects and more cost effectiveness than synthetic products (Belay, 2008; Khan et al., 2005; Lykkesfeldt and Svendsen, 2007). Baojiang (1994) reported that Spirulina is good for the beneficial intestinal flora which also helps in the effective utilization of feed and easy conversion of feed to animal protein by the broiler. But when $100 \%$ Spirulina was added with feed for the replacement of total synthetic vitamin-mineral premix and that was also supported by the result of the experiment conducted by Toyomizu et al. (2001) that increases the addition Spirulina in feed will depress the production and feed conversion ratio.

\section{Carcass characteristics}

Raach-Moujahed et al. (2011) stated that Spirulina improved the carcass yield of Arbor Acres broiler. A similar result was observed by Razafindrajaona et al. (2008) who found that Spirulina incorporated according to $100 \mathrm{mg} / \mathrm{kg}$ body weight, improve the carcass yield. According to Razafindrajaona et al. (2008), the improvement of the carcass yield indicates a better development of the thighs and the breast which also support the result of the present experiment, when $50 \%$ synthetic vitamin-mineral premix were replaced by Spirulina from Myanmar as maximum thigh and breast weight was found in this group of broiler. Jansons and Jemeljanovs (2010) established that the applied phytogenic supplements improve the quality of the final product as the slaughter weight increases with $4.4 \%$ and the content of muscular tissue in the carcass increases with $2.7 \%$.

\section{Blood profile}

Torres-Duran et al. (1998) and Fonget al. (2000) reported a significant reduction of triglycerides and cholesterol concentrations for rats or mice fed Spirulina diets which supports the result of the present experiment. Cholesterol concentration was lower in T4 where $50 \%$ vitamin-mineral premix is replaced by $50 \%$ Spirulina from Myanmer. The most widely published metabolic effect of Spirulina is the anticholesterolaemic effect, which have supported our results because cholesterol concentration was lower in Spirulina treated group. 
Tsuchihashi et al. (1987) and Marieyet al. (2012) reported that the significant reduction in plasma cholesterol of broiler chickens fed dietary Spirulina could be attributed to reduce the absorption and/or synthesis of cholesterol in the gastro-intestinal tract by Spirulina supplementation that increase Lactobacillus population. Lactobacillus has found to have a high bile salt hydrolytic activity and to reduce the cholesterol in the blood by de-conjugating bile salts in the intestine (Surono, 2003), thereby preventing them from acting as precursors in cholesterol synthesis (Abdulrahimet al., 1996). Concentration of plasma total protein, albumin and globulin may be related to the high level and good quality of protein contents in Spirulina (55$65 \%$ ) which was also in the agreement with result of the present experiment because albumin concentration in blood plasma was maximum in T5. These results are in line with the findings of Tewe (1985) and Eggum (1989), who stated that total serum protein, globulin and albumin were directly responsive to protein quantity and quality.

\section{Conclusion}

From the present result, it may conclude that, replacement of synthetic vitamin mineral premix by Spirulina could increase production performance of broiler as well as it could reduce the cholesterol concentration and increase protein synthesis as Spirulina is a good source of protein having amino acid in well proportion that we found by analysing the concentration of albumin in blood plasma. But source and inclusion level of Spirulina have also impact on broiler production that was observed in the present study. Spirulina from Myanmar is better than China and $50 \%$ synthetic vitamin mineral premix could be replaced by using $50 \%$ Spirulina which would be helpful for safe broiler production.

\section{Acknowledgment}

Authors deeply acknowledge the Bangladesh Agricultural Research Council (BARC), Dhaka, Bangladesh for financial support to conduct the research. Authors also acknowledge the JUNE Pharmaceuticals Limited, Myanmar for providing Feed grade Spirulina to support the research.

\section{Conflict of interest}

There is no conflict of interest among the authors.

\section{References}

Abdulrahim SM, MSY Haddadin, EAR Hashlamoun and RK Robinson (1996). The influence of Lactobacillusacidophilus and bacitracin on layer performance of chickens and cholesterol content of plasma and egg yolk. British Poultry Science 37(2):341-346.

AOAC (1990). Official Method of Analysis (15 th Edt). Association of Official Analytical Chemists. Washington D. C., U.S.A.

Baojiang G (1994). Study on effect and mechanism of polysaccharides on Spirulinaplatensis on body immune functions improvement. Second AsiaPacific Conference on Algal Biotechnology 24: 25-27.

Belay A (2008). Spirulina (Arthrospira): Production and Quality Assurance. Spirulina in Human Nutrition and Health (CRC Press)pp. 1-25.

Belay A, T Kato and YOta(1996). Spirulina (Arthrospira): Potential application as an animal feed supplement. Journal of Applied Phycology 8: 303-311.

Blum JC, S Guillaumin, C Calet(1976). Valeur alimentaire des algues Spirulines pour la poule pondeusse. Annales de la Nutrition et de I'Alimentaire 30: 675-682.

Carroll JA, NE Forsberg (2007). Influence of stress and nutrition on cattle immunity. Veterinary Clinics Food Animal Practice 23 : 105-49.

Caspary WF(1992). Physiology and pathophysiology of intestinal absorption. The American Journal of Clinical Nutrition 55:299S-308S.

Devi A, M Subbulakshimi, G Madhavi Devi, and LV Venkataram (1981). Studies on the proteins of mass cultivated, blue-green alga (Spirulina platensis). Journal of Agriculture and Food Chemistry 29: 522-525.

Eggum BO (1989). Biochemical and Methodological Principles. In: Rock, HD Eggum, BO Low, AG Simon and $T$ Zebrowska, (Eds.). Protein Metabolism in Farm Animals, Oxford Science Publications. Berlin.1-52.

Fong B, M Cheung and M Lee (2000) Effect of dietary Spirulina on plasma cholesterol and triglyceride levels in mice. In: Abstracts. 4th Asia-Pacific Conference on Algal Biotechnology.pp.150.

Habib MAB, M Parvin, TC Huntington, MR Hasan (2008). A Review on Culture, Production and Use of Spirulina as Food for Humans and Feeds for Domestic Animals and Fish. Food and Agriculture Organization of The United Nations. Rome.FAO Fisheries and Aquaculture Circular No. 1034 FIMA/C1034 (En). ISSN 2070-6065.

Holman BWB and AEO Malau-Aduli (2012). Spirulina as a livestock supplement and animal feed. Journal of Animal Physiology and Animal Nutrition 97: 615-623.

Jansons I and A Jemeljanovs(2010). The influence of phytogenic additives on pig productivity, carcases and quality. Research Institute of Biotehnology and Veterinary Medicine 'Sigra', 
Latvia University of Agriculture,Institutast. L, Sigulda, Latvia, LV 2150

Kelly J, Moorhead and CM Helen (1995). Spirulina, Nature's superfood, Illustrated by Sunny pau ole, Published by Nutrex,Inc 2nd Printing USA.

Khan AM, SA Sarker, NH Alam, MS Hossain, G] Fuchs, MA Salam (2005). Low Osmolar Oral Rehydration Salts Solution in the Treatment of Acute Watery Diarrhoea in Neonates and Young Infants: A Randomized, Controlled Clinical Trial Journal of Health, Population and Nutrition, 23(1): 52-57.

Kharde SD, RN Shirbhate, KB Bahiram, SF Nipane (2012). Effect of Spirulina supplementation on growth performance of broilers. Indian Journal of Veterinary Research 21: 66-69.

Lykkesfeldt J andO Svendsen (2007). Oxidants and antioxidants in disease: oxidative stress in farm animals. Veterinary Journal 173(3): 502-511.

Mariey YAHR, MA Samak and Ibrahem (2012). Effect of using Spirulinaplatensis algae as a feed additive for poultry diets: 1- productive and reproductive performances of local laying hens. Egyptian Poultry Science 32 (I): 201-215.

Pesti GM andRI Bakalli(1998). Studies on the feeding of cupric sulphatepentahydrate and cupric citrate to broiler chickens. Poultry Science 75: 1086-1091.

Raach-Moujahed A, S Hassani, S Zairi, M Bouallegue, C Darej, B Haddad and C Damergi (2011). Effect of dehydrated Spirulinaplatensis on performances and meat quality of broilers. Research opinions in animal and veterinary sciences 1(8): 505-509.

Razafindrajaona JM, JN Rakotozandriny, R Rakotozandrindrainy, AT Sivingaina, KD Ramapiherika and JN Randria (2008). Influence de l'incorporation dans les provendes de la spiruline de Madagascar (Spirulinaplatensis var. toliarensis) sur la croissance des poulets de chair. International Symposium on SpirulinaToliara Sud-Ouest de MADAGASCAR. Avril 2008.
Richmond A (1987). Handbook of microalgal culture. Beckwell, Oxford.

Shanmugapriya B, S SaravanaBabu, T Hariharan, S Sivaneswaran, MB Anusha(2015).Dietery administration of Spirulinaplatensis as probiotics on growth performance and pathology in broiler chicks. International Journal of Recent Scientific Research 6: 2650-2653.

Shuvo AK (2001). Spirulina is future food. Professors. Current Affairs pp. 78.

Sujatha T and D Narahari(2011). Effect of designer diets on egg yolk composition of 'White Leghorn' hens. Journal of Food Science and Technology 48: 494-497.

Surono IS (2003). In vitro probiotic properties of indigenous Dadih lactic acid bacteria AsianAustralian Journal of Animal Science 16: 726731.

Tewe OO (1985). Protein metabolism in growing pigs fed corn or cassava peel based diets containing graded protein levels. Research in VeterinaryScience 38(3): 259-63.

Torres-Duran PV, R Miranda-Zamora, MC ParedesCarbajal, D Mascher, JC Diaz-Zagoya, M JuarezOropeza (1998). Spirulina maxima prevents induction of fatty liver by carbon tetrachloride in the rat. Biochemistry and molecular biology international 44: 787-793.

Toyomizu M, K Sato, HTaroda, T Kato andY Akiba (2001). Effects of dietary Spirulina on meat colour in muscle of broiler chickens. British Poultry Science 42: 197-202.

Tsuchihashi N, T Watanabe, Y Takai (1987). Effect of Spirulinaplatensis on caecum content in rats. Bull Chiba Hygiene College 5:27-30.

Windhorst HW (2006). Changes in poultry production and trade worldwide. World's Poultry Science Journal62: 585-602.

Yoshida M and H Hoshi (1980). Nutritive value of Spirulina, green algae, for poultry feed. Japan Poultry Science 17: 27-30. 